\title{
Effects of Climate Change on Rice Production at Khulna district, Bangladesh
}

\author{
Nuralam Hossain ${ }^{(1,2)^{*}}$, ASM Saifullah ${ }^{(2)}$, Shameem Hassan Bhuiyan ${ }^{(3)}$, Nasir \\ Uddin $^{(4)}$, Mijanur Rahman ${ }^{(5)}$ \\ ${ }^{(1)}$ Faculty of Urban Construction and Environmental Engineering, Chongqing University, Chongqing, \\ 400045, China \\ ${ }^{(2)}$ Department of Environmental Science and Resource Management, Mawlana Bhashani Science and \\ Technology University, Santosh, Tangail-1902 \\ ${ }^{(3)}$ Bangladesh Meteorological Department, Ministry of Defense, Dhaka-1207, Bangladesh \\ ${ }^{(4)}$ Institute of Water and Flood Management (IWFM), Bangladesh University of Engineering and \\ Technology (BUET), Bangladesh \\ ${ }^{(5)}$ Climate Change and Protected Area Management Officer, USAID's Climate Resilient Ecosystems \\ and Livelihoods, South-West Region, Khulna, Bangladesh
}

Received: 13 December 2018

Accepted: 30 June 2019

Published online: 30 December 2019

\begin{abstract}
In Bangladesh 164 million people depend on rice but due to climate change (CC) vulnerabilities the yield of rice is severely reducing. Therefore, this study aimed to explore the effects of CC on rice yield using recent trend analysis, Mann-Kendall (MK) trend test and correlation. For this study, the required climate and selected rice production data were collected from Bangladesh Meteorological Department (BMD) and Department of Agriculture Extension (DAE), Khulna. In time series statistics both parametric and nonparametric methods were applied to detect a monotonic trend of climatic variability and Aman rice production. Correlation between climatic variability and rice production was also investigated. The study exposed that the temperature and rainfall had an increasing trend and statistically significant whereas the relative humidity found decreasing. Overall, the bright Sunshine had positive trend but week. According to nonparametric trend test of climatic variability and Aman yield only minimum temperature showed a positive trend which found statistically significant. In contrast, Mann-Kendall trend test revealed that rainfall had positively significant while temperature had negative significant. The correlation revealed the Aman production is a strong response with minimum temperature whereas the Lona Coche showed a positive correlation with maximum temperature. The variation of Aman production exhibited a positive correlation with both Rainfall and humidity respectively and Lona Coche found a negative correlation. The sunshine had a week correlation against both yields. The findings suggest should give attention of temperature-tolerant rice varieties to mitigate possible adverse effects of CC.
\end{abstract}

Keywords: climate change, trend analysis, Mann-Kendall (MK) test, Rice Production, Bangladesh

${ }^{*}$ Corresponding author: Nuralam Hossain

e-mail: nuralam_esrm@yahoo.com 


\section{Introduction}

The economy of Bangladesh is predominately by agricultural which accounts for about $35 \%$ of the gross domestic product (GDP) (Mistri et al. 2015). The country has achieved plenty of growth in rice production due to substantial cropping intensification, introduction of high yielding and saline tolerant rice varieties, expansion of irrigated areas and increased use of chemical fertilizers (Masud et al. 2014). Bangladesh is considered as the $4^{\text {th }}$ largest rice producer in the world, and it comprises an area of about 11.10 million ha. for rice production (Hossain et al. 2008) whereas about $80 \%$ of the total cultivable land is being used for the production of rice (BBS 2002). This largest sector agriculture is already under stress due to huge demands for food, and from problems of agricultural land and water resources depletion (Mistri et al. 2015; Amin et al. 2015). However, recently Bangladesh is facing a serious challenge in rice production to feed the over population in the context of shrinking cultivable land and impact of CC. Ahmed and Alam (1999) reported that, Global warming induced changes in temperature and rainfall are becoming evident in global scale, as well as in our country. Hazards like floods, droughts, cyclones and others, which are aggravated by climate change and its variability being experienced more frequently in Bangladesh than ever before. Uncertainty of rainfall and uneven temporal and spatial distribution in one hand, creating flooding and of the other hand longer dry spells evoking droughty conditions (Lai, et. al. 1998; Masud et al. 2014).

Climatic factors such as temperature, rainfall, humidity and solar radiation are closely linked with agricultural production. Reduction in rice productivity has been predicted to be a major concern in years to come due to changing climatic conditions (Yuji et al. 2009). The effects of CC on rice yield are now emerging concern all over the world (Rimi et al. 2009). According to IPCC (2007), CC greatly influences the agricultural productivity especially crop yields vary considerably due to the higher and lower level temperature. Findings also reported that a little rainfall in early February help the cultivation of Boro to a significant extent while heavy local level rainfall may lead to severe floods in late August, which may reduce the significant suitable area for Aman cultivation. Rainfall is one of the important climatic factors for crop production (Karim et al. 1999). All crops have critical stages when it needs water for their growth and development. Moreover, excessive rainfall may cause flooding and water logging conditions that also lead to crop loss (WB 2000). If rainfall increases by $1 \mathrm{~mm}$ it will decrease Aman rice production at their vegetative, reproductive and ripening stages (Amin et al. 2015). CC and its effect on rice production and about $74.31 \%$ of the principle crops Aman and $100 \%$ of Boro cropland has been damaged in the south-western part of Bangladesh due to flood remains for half of the year and the cropland is badly affected by salinity intrusion (Seal and Baten 2012). Boro rice is a potential source of production, which currently accounts for about $50 \%$ of total rice production in the country (BRRI 2006). CC in the south-west region of Bangladesh creates insecurities for food, water, human life, property, settlement, livelihood assets, livelihoods and others (MOEF 2009).

Recently, the studies of CC and its effects on rice production have gained attention. Rimi et al. (2009) conducted a study on Trend analysis of climate change and investigation on its probable impacts on rice production at Satkhira, Bangladesh. The findings of that study revealed that, the production of Aus rice summer crop decreased significantly with increasing maximum temperature, while the winter crop Boro production increased significantly with the increase of minimum temperature when the interannual amount of winter season rainfall fluctuation was little. Therefore, the production of Boro rice was insignificantly affected by these variables. In most cases, the study found that irrespective of crops and Global Climate Models (GCMs), climate change would have an adverse on rice yield. Another study conducted by Chowdhury and khan (2015) on the impact of climate change on rice yield in Bangladesh: a time series analysis. The results showed that, significant influence of climate variables on rice yield. The maximum temperature was statistically significant and negatively affects the production of rice and the minimum temperature had highly significant which was a positive impact on 
the yield of Boro rice only. The rainfall was found significant for all rice yields with positive effects on Aus and Aman and adverse effects on Boro. The humidity also has significant effect on the yield of all three rice.

Amin et al. (2015) reported that, the effects of all the climate variables have significant contributions to the production of major food crops. The maximum temperature significantly affects the yield of all food crops' except Aus rice whereas; minimum temperature insignificantly affects Aman rice. Similarly, rainfall significantly benefits cropping area of Aus rice, but significantly affects both yield and cropping area of Aman rice. Usually, humidity was found positively correlated with the yield of Aus and Aman rice but, negatively influenced the cropping area of Aus rice besides. Sunshine also has significant influence on Boro rice yield (Zhang et al. 2014; Ferdous and Baten 2011; Mirza 2002). There are number of studies, climate change and its impact on rice production but a few have intensively examined the relationship between CC and crop production (Ferdous and Baten 2011; Amin et al. 2015). So, it is necessary to assess the potential impacts $\mathrm{CC}$ and rice production between high yield variety and local variety for an understanding of the national impacts of recent climate trend on principal food grain would help to anticipate impacts of future $\mathrm{CC}$ on the food security of the country.

In Bangladesh, the principal crop-growing period is divided into two main seasons, Rabi and Kharif. The Rabi season starts to form the month of November and ends on April during this time the rainfall availability is very little whereas the Kharif season starts from May and ends in October when the moisture supply from rainfall is enough to support rain-fed or unirrigated crops (Chowdhury and khan 2015). According to SRDI 2000, the defining study area consists of one Agroecological Zone (AEZ) of Bangladesh namely; Ganges Tidal Floodplain (AEZ-8); the extent of the entire AEZ is 17,066 sq.km. Acid sulphate soil occupies a significant part of the area, where it is extremely acidic during the dry season. Most of the top soils are acidic and sub soils are neutral to mildly alkaline (Rimi et al. 2009). Therefore, the main objective of this study was to explore the effects of $\mathrm{CC}$ on rice (two specific varieties) production by statistical analysis of recent trend, Mann-Kendall (MK) test and correlation.

\section{Methodology}

\section{Study area}

This study was conducted at the Koyra upazila under Khulna District of Bangladesh. The occupying area is $1775.41 \mathrm{sq} \mathrm{km}$, located in between $22^{\circ} 12^{\prime}$ and $22^{\circ} 31^{\prime}$ north latitudes and in between $89^{\circ} 15^{\prime}$ and $89^{\circ} 26^{\prime}$ east longitudes. It is bounded by Paikgacha upazila on the north, the Bay of Bengal and Sundarban on the south, Dacope upazila on the east, Assasuni and Shyamnagar upazila on the west. The main water bodies Main rivers: Dharla, Pasur, Arpngachia, Taldhup, Malancha, Kobadak, ball; Koyra canal is notable (Masud et al. 2014; Banglapedia 2014). As the study area is located near the world largest mangrove forests named Sundarbans (UNESCO, world heritage site). The highest temperature observes in April and May while lowest in December and January. The region has high relative humidity (80-90\%) with mean annual rainfall ranges from about $1900 \mathrm{~mm}$ to $2500 \mathrm{~mm}$. June, July and August are the wettest months while December, January and February the driest (Hossain et al. 2016).

\section{Data acquisition and interpretation}

The required rice production and climate data, specifically of Khulna were gathered from authentic organizations. The climatic data (maximum and minimum temperature, relative humidity, total rainfall and bright sunshine) was assembled from Bangladesh Meteorological Department (BMD 2013). The district level rice production data on selected variety (Aman-Upshi and Lona Coche-local variety) were collected from the Department of Agricultural Extension (DAE) Khulna for the period of 
1994 to 2010. The rice yield data was not recoded previous years of 1994. The independent variables of this study were maximum temperature, minimum temperature, rainfall, relative humidity and the sunshine. The computation of climatic variability and yield production was done with the help of XLStat software for non-parametric analysis.

\section{Data analyses}

In the present study, the linear and monotonic trend was investigated mostly annual, seasonal and monthly time series data with short term and long-term pattern of climatic variability and yield in the study area. The parametric method is used so that sum of squared error becomes the least. In trend analysis, it is most widely accepted techniques and is most robust in case of normally distributed data. Where the distribution of the variable is not Gaussian the non-parametric technique be more appropriate in the analysis of trend. Both parametric and non-parametric techniques were used to investigate the trend in different climatic variable and yield in order to their relative strength and weakness. In parametric and non-parametric trend test were applied by employing t-test and Mann-Kendall (MK) test and Sen' Slop estimation.

\section{Trend Analysis and examined effects on Rice Production}

In order to know the variability of each climatic parameter and rice yield during the period of 1980-2010, the analysis work is done recent trend to identify the variation of each climatic parameters. The data were analyzed in year basis to explore the recent variation. To find out a variation of annual rice production against the various climate variables a possible correlation has done.

\section{Results and discussion}

\section{The trend of maximum and minimum temperature}

The trend of annual average maximum temperature is increasing in the study area over the period of (1980-2010), which is a positive trend and statistically significant. Figure 1 reveals that the annual average maximum temperature is rising and the rate of the trend is $0.023^{\circ} \mathrm{C} / \mathrm{yr}$. Figure 2 shows that the annual average minimum temperature is slightly increasing trend and the rate of the trend is $0.079^{\circ} \mathrm{C} / \mathrm{yr}$, which is regular and medium positive trend.

\section{The trend of annual total monsoon rainfall}

The analysis depicts that, the trend of annual total monsoon rainfall distribution through the period of 1980-2010 in the study area is rising but weak positive Figure 3. However, the pattern of rainfall distribution is irregular and not significant statistically. The trend is rising and the rate is 0.787 $\mathrm{mm} / \mathrm{yr}$. Therefore, the trend of monsoon rainfall pattern over the period has been altered.

\section{The trend of relative humidity and bright sunshine}

Figure 4, exhibits that the trend of annual average relative humidity is also decreasing which is a negative and irregular trend. Therefore, the trend is downing at $0.020 \% / \mathrm{yr}$. on the other hand, the trend analysis of annual average bright sunshine over the period 1980-2010 could reveal that, it had slight increasing which is positive but medium trend Figure 5.

The Non-parametric trend test of climatic variability and Aman yield revealed that, all parameters were no significant except minimum temperature (Tab. 1). According to the $Q$ value the 
Environment, Earth and Ecology Vol. 3 No. 1 (2019), 42 - 54

N. Hossain et al.

significance level of minimum temperature at 0.056 which is a positive and statistically significant trend.

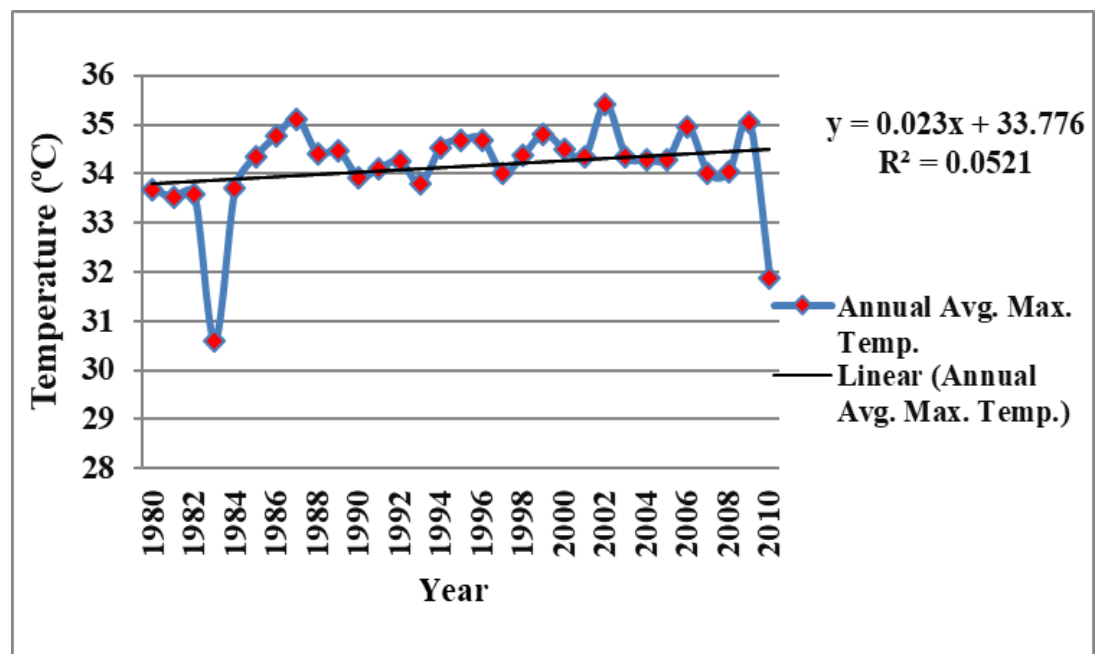

Fig. 1. Trend of annual average maximum temperature.

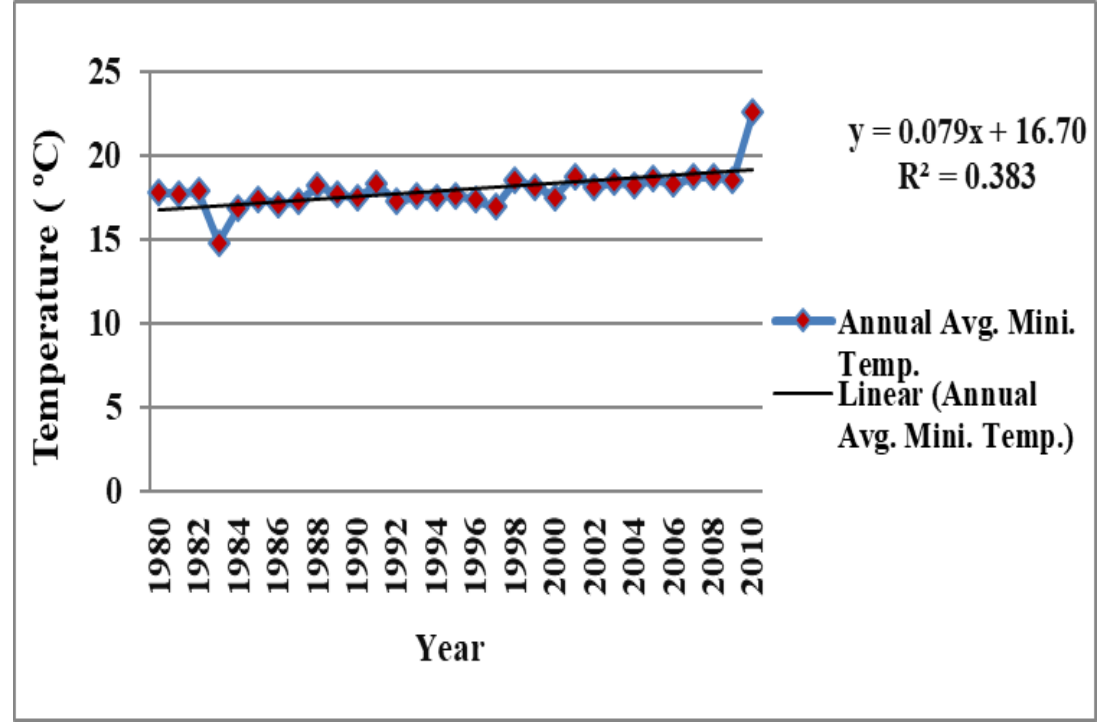

Fig. 2. Trend of annual average minimum temperature.

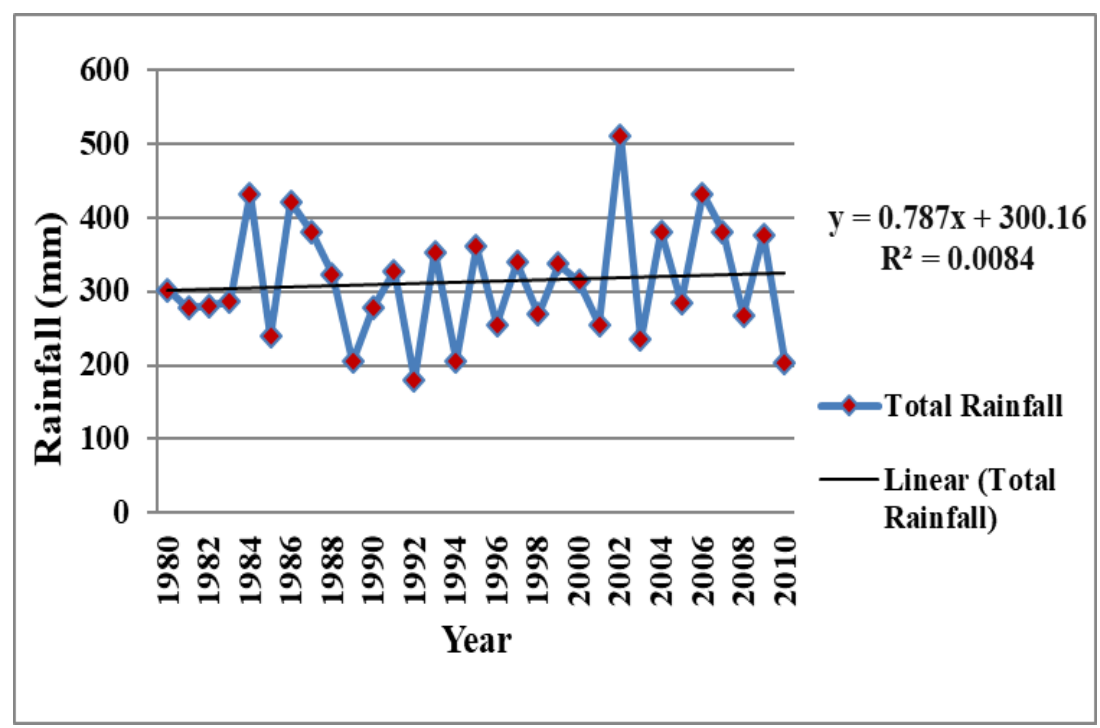

Fig. 3. Trend of annual total monsoon rainfall. 


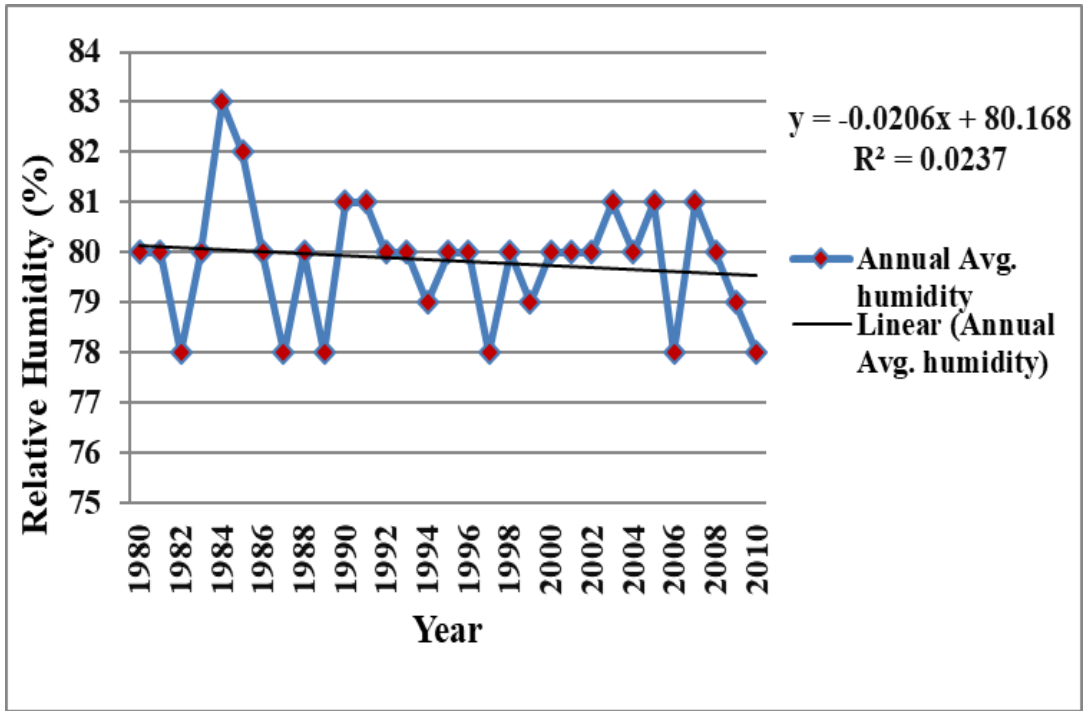

Fig. 4. The trend of annual average humidity.

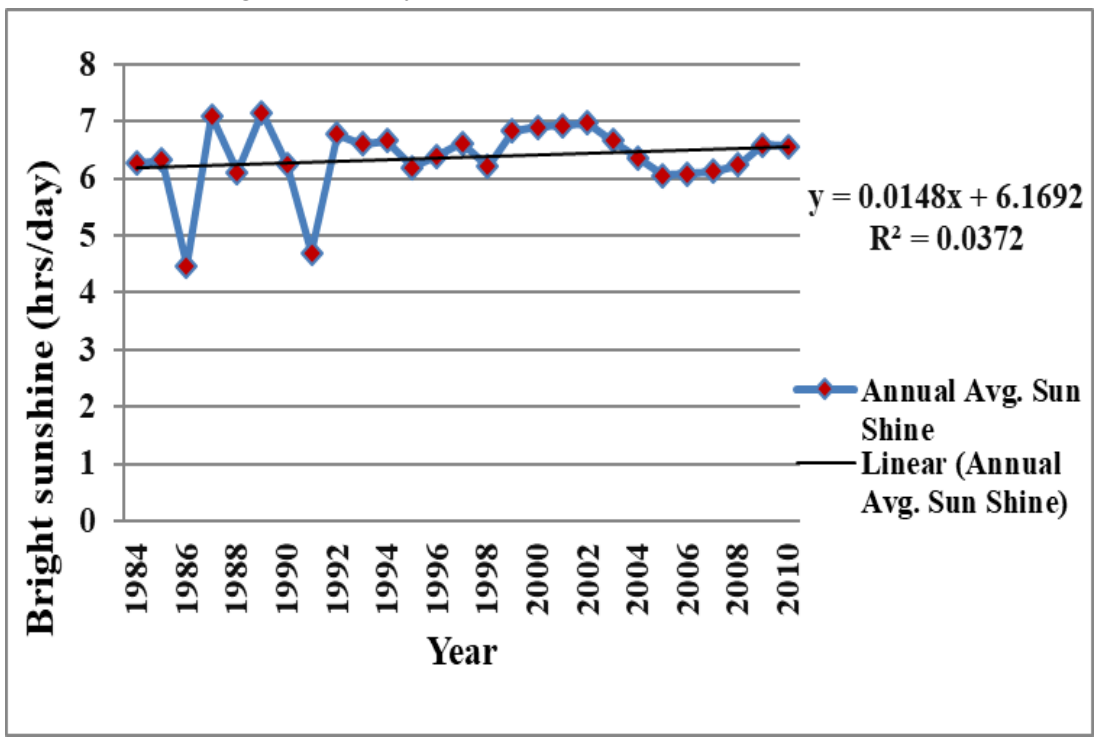

Fig. 5. Trend of annual bright sunshine.

Tab. 1. Non-parametric trend test of climatic variability and Aman yield.

\begin{tabular}{|c|c|c|c|c|c|c|}
\hline $\begin{array}{l}\text { Number of } \\
\text { observation }\end{array}$ & Parameter & $\begin{array}{l}\text { Mann- } \\
\text { Kandall (MK) } \\
\text { test (Z) }\end{array}$ & $\begin{array}{l}\text { Significant } \\
\text { level }\end{array}$ & $\begin{array}{l}\text { Sens' Slop } \\
\text { estimation } \\
\text { (Q) }\end{array}$ & $\begin{array}{l}\text { Year of } \\
\text { observation }\end{array}$ & variables \\
\hline 30 yrs. & $\begin{array}{l}\text { Max } \\
\text { Temperature }\end{array}$ & 1.58 & NS & 0.024 & \multirow{4}{*}{ 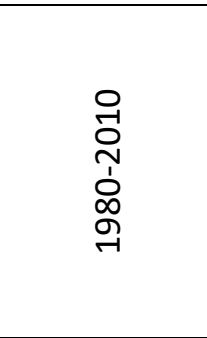 } & \multirow{5}{*}{ 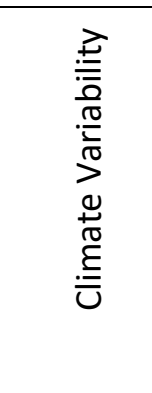 } \\
\hline 30 yrs. & $\begin{array}{l}\text { Min } \\
\text { Temperature }\end{array}$ & 3.94 & $* * *$ & 0.056 & & \\
\hline 30 yrs. & Rainfall & -0.20 & NS & -1.385 & & \\
\hline 30 yrs. & $\begin{array}{l}\text { Relative } \\
\text { Humidity }\end{array}$ & -0.57 & NS & 0.000 & & \\
\hline 26 yrs. & Sunshine & 0.08 & NS & 0.002 & $1984-2010$ & \\
\hline 10 yrs. & Aman & -0.31 & NS & -0.010 & $2000-2010$ & \multirow[t]{2}{*}{ Yield } \\
\hline 10 yrs. & Lona Coche & -0.39 & NS & -0.013 & $2000-2010$ & \\
\hline
\end{tabular}

${ }^{*} \alpha=0.001$ level of significance, ${ }^{* *} \alpha=0.01$ level of significance, ${ }^{* * *} \alpha=0.05$ level of significance, $\mathrm{NS}=\mathrm{No}$ significant 


\section{Correlation between yield and climatic variability}

The correlation between Aman production and minimum temperature in the study area over the period of (1994-2010) shows that, the trend is strongly positive which statistically highly significant Fig. 6 (a). But for the Lona Coche production the trend has found negative Fig. 6(b). The Fig. 7 (a) exhibits, that the variation of Aman production with annual maximum temperature is also showing negative trend while of Lona Coche production has found increasing trend which is statistically positive Fig. 7 (b). Therefore, the high yield variety Aman can grow within lower and medium higher-level temperature whereas; the local variety Lona Coche might not tolerate the lower and higher-level temperature.

It is revealed from Fig. (8a) that, the variation of Aman production with annual monsoon rainfall in the study area over the period of (1994-2010) had an increasing trend which is statistically positive correlation. While the Lona Coche production trend was found decreasing with annual monsoon rainfall which is statistically strongly negative, Fig. 8 (b). Although, Aman is rain-fed crop, the abundant production of Aman depends on the regular monsoon rainfall but the negative trend of rainfall may adversely affect the production of Lona Coche yield (Fig. 8 b).

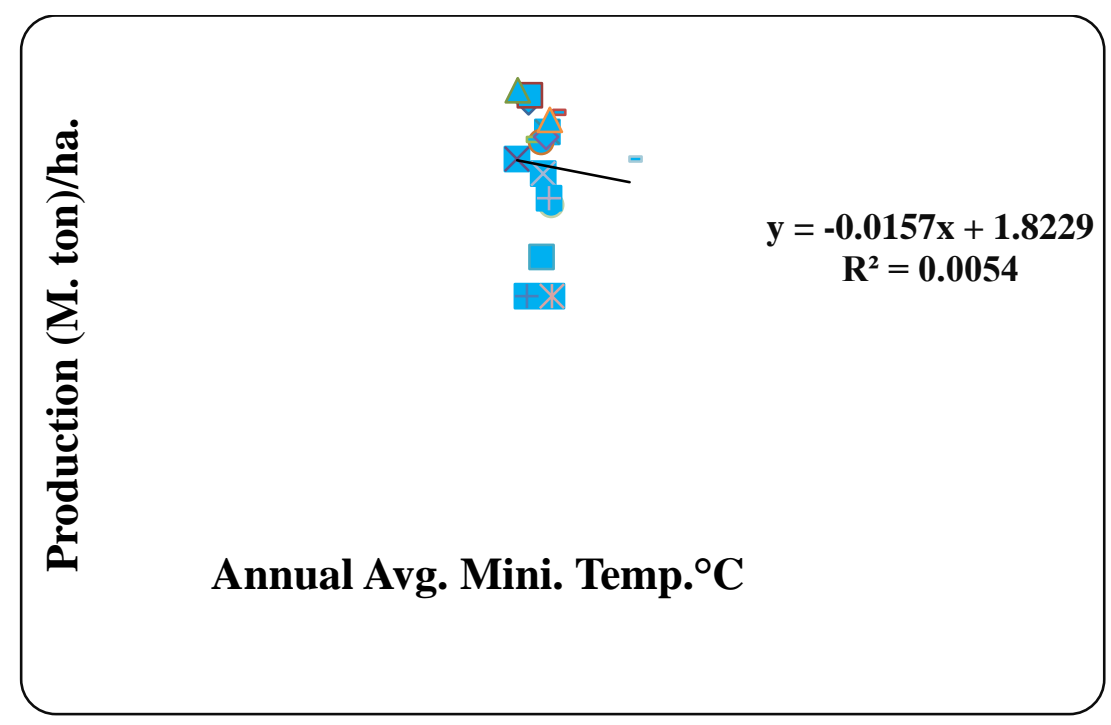

Fig. 6a. Correlation between Aman production and minimum temperature period (1994-2010).

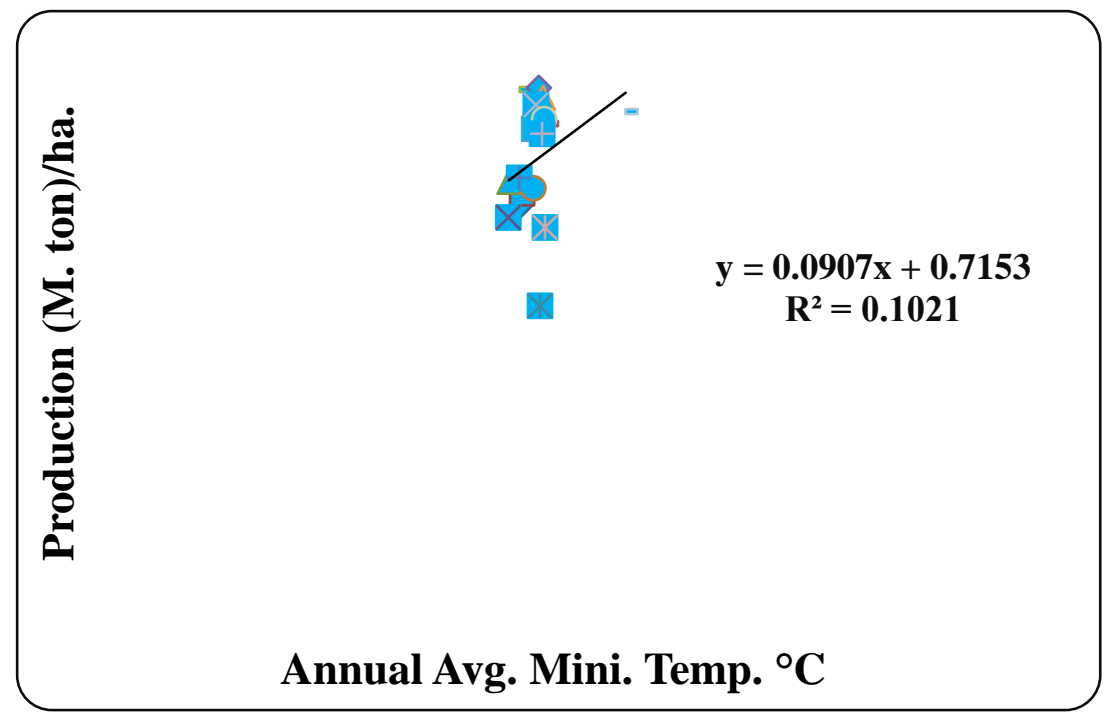

Fig. 6b. Correlation between Lona Coche production and minimum temperature period (1994-2010). 
The variation of Aman production with annual relative humidity had a positive trend but week correlation Fig. 9 (a, b). On the other hand, the yield of Lona Coche has found decreasing trend against relative humidity which is statistically negative Fig. 9 (b). The higher relative humidity is always favorable for the higher production of crops as its influence the plant development and photosynthesis of the leaves (Masud-Al et al. 2014). Therefore, the relative humidity has an observable effect on Local variety production.

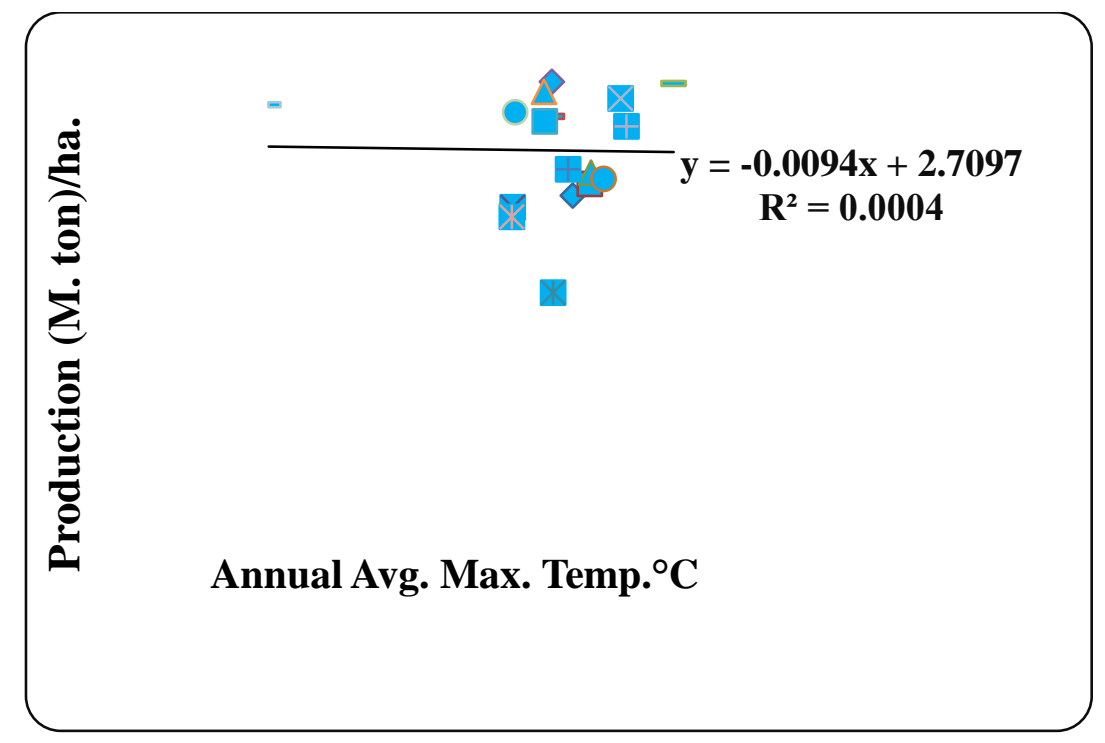

Fig. 7a. Correlation between Aman production and maximum temperature period (1994-2010).

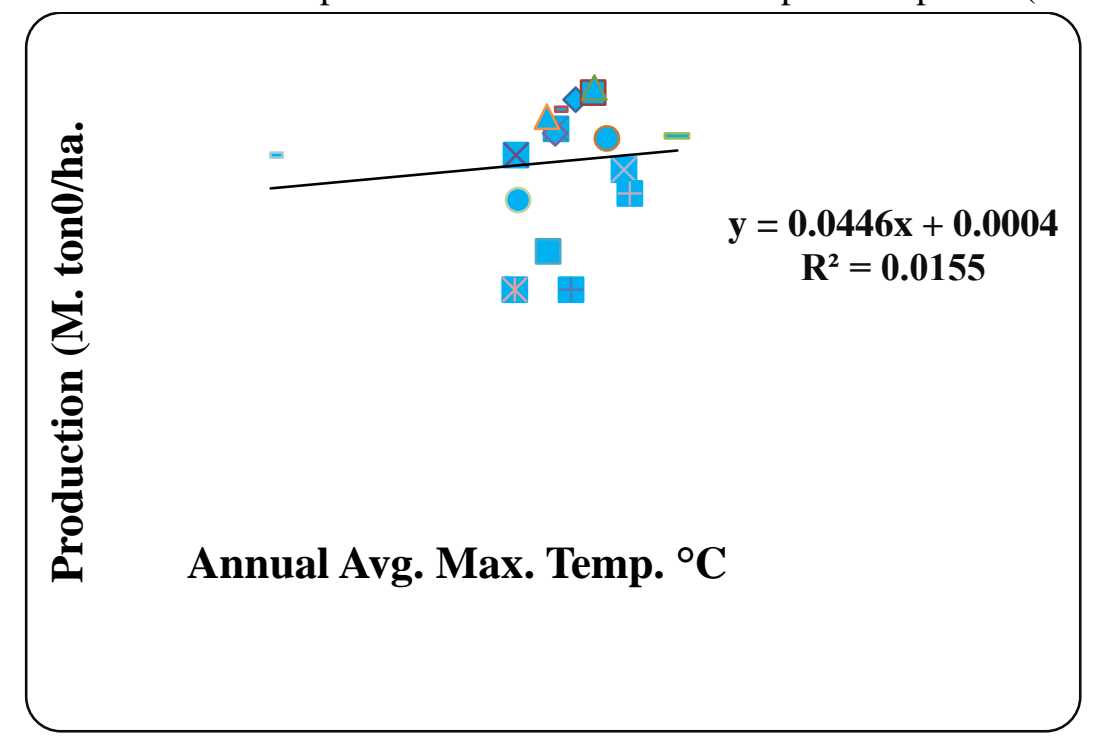

Fig. 7b. Correlation between Lona Coche production and maximum temperature period (1994-2010).

The correlation between crop production and bright sunshine also revealed a positive response but weak Fig. 10 (a, b). However, the solar radiation affects many physiological processes of the plant, particularly photosynthesis. The light requirement varies with plant species (Ali 2010). There are critical stages of plant growth when solar radiation is especially important. For the same amount of daily solar radiation, the photosynthesis rate increase with day length (Marshall and Haferkamp 1988).

The Mann-Kendall test revealed that, the trend of monsoon rainfall had medium significance $\left({ }^{* *} \alpha=0.01, \mathrm{z}=2.67\right)$ for the month of September while the trend of temperature had week significance. The rice production had found week significant both for the monsoon rainfall and temperature. 


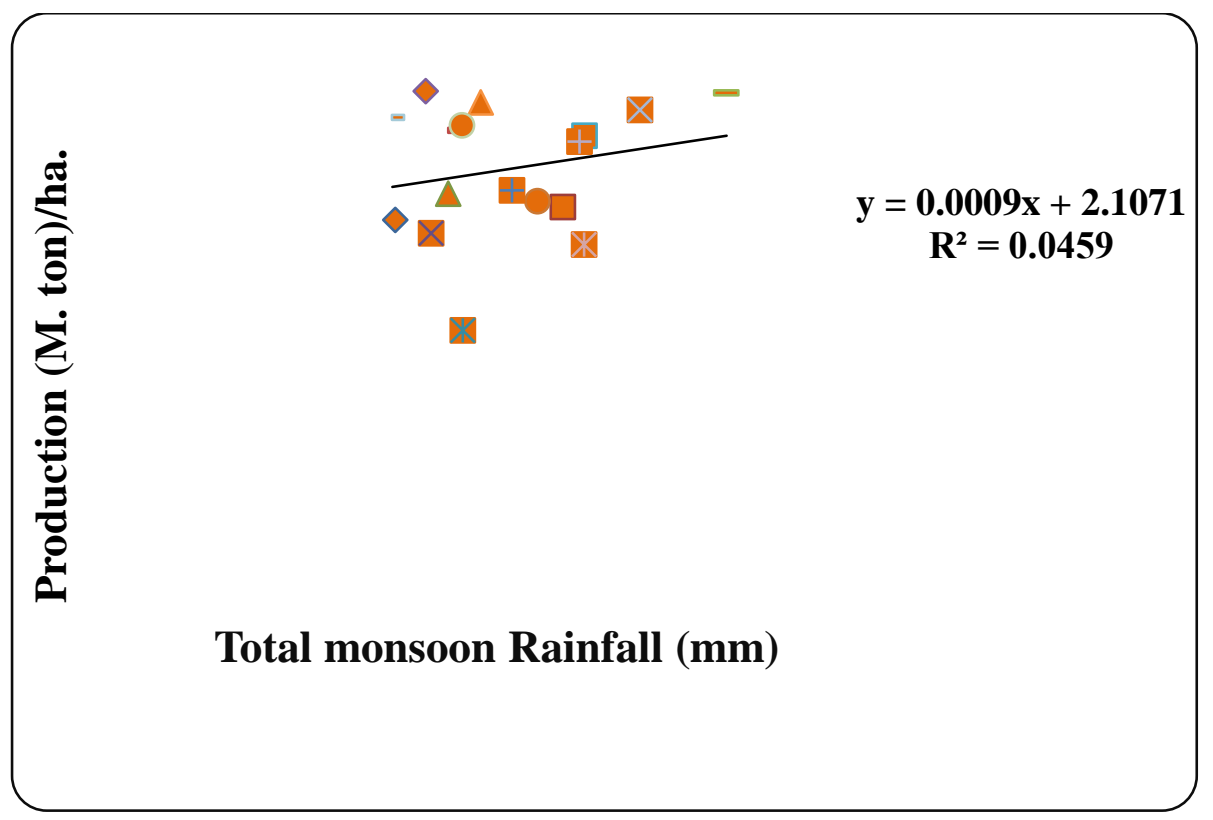

Fig. 8a. Correlation between Aman production and total monsoon rainfall period (1994-2010).

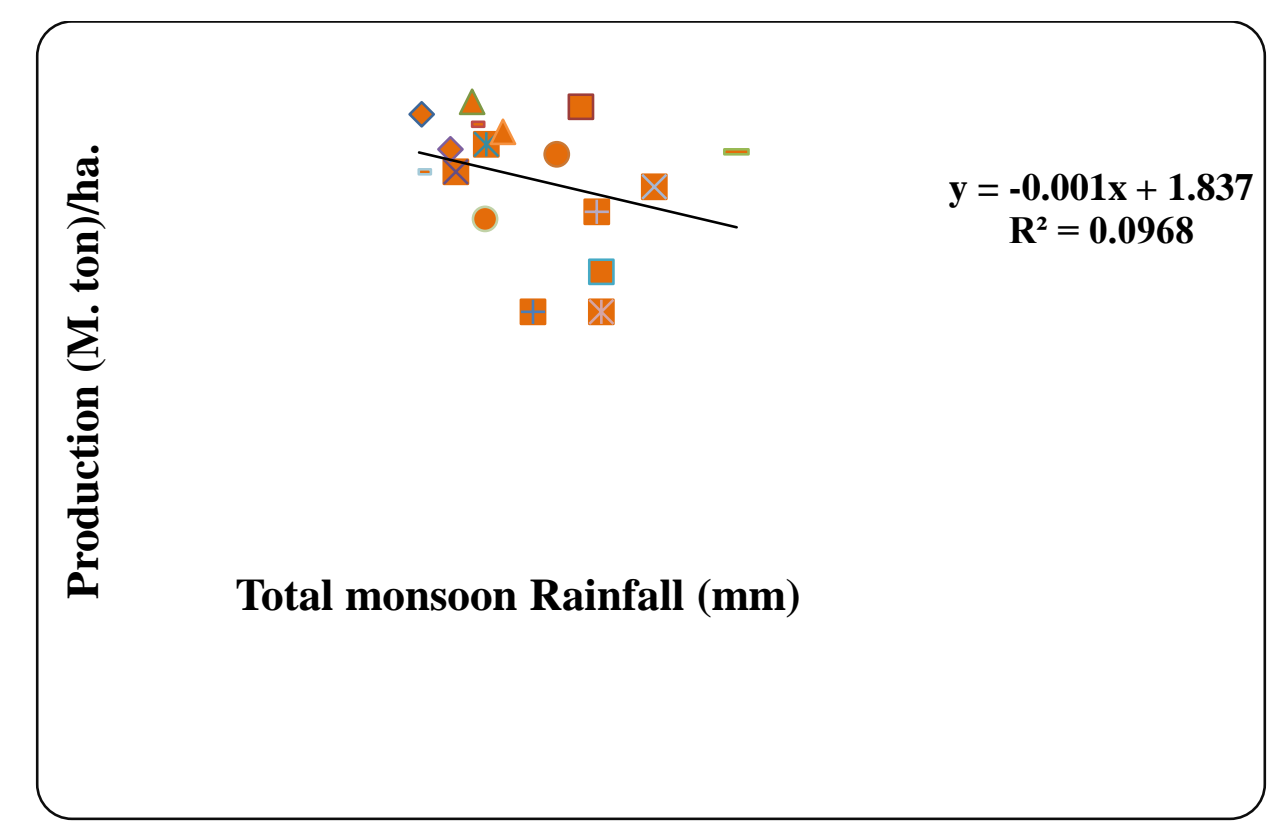

Fig. 8b. Correlation between Lona Coche production and total monsoon rainfall period (1994-2010).

\section{Conclusion}

The study attempted to examine the effects of climate change on specific rice variety between high yield variety Aman (Upshi) and Lona Coche (local variety). The effects of climate change on rice yield depend on actual patterns of climatic factors also differences of local growing seasons, crop management. Both higher level and lower level of temperature may decrease rice yield due to spikelet sterility and higher respiration losses. The time series analysis exhibited that, the trend of temperature and total rainfall had an increasing which was statistically positive whereas the relative humidity had found decreasing. Overall, the bright sunshine had positive trend but week. In addition, the nonparametric trend test of climatic variability and Aman yield only minimum temperature showed a positive trend which statistically significance. In contrast, Mann-Kendall trend test found, rainfall had 
positively significant while temperature had negatively significant. The findings indicated that the climatic variables have substantial effects on the both production of Aman and Lona Coche. According to correlation, the Aman production had a strong response with minimum temperature whereas the Lona Coche showed a positive correlation with maximum temperature. The variation of Aman production exhibited a positive correlation with both Rainfall and humidity respectively and Lona Coche found a negative correlation. The sunshine had a week correlation against both yields. Due to climate change effect, the production of Lona Coche has been affected; it means that the variety cannot tolerate the lower temperature, excessive rainfall and high relative humidity. The future challenge would focus on salt and temperature-tolerant high yield rice varieties to mitigate possible adverse effects of $\mathrm{CC}$ to ensure sustainable agriculture.

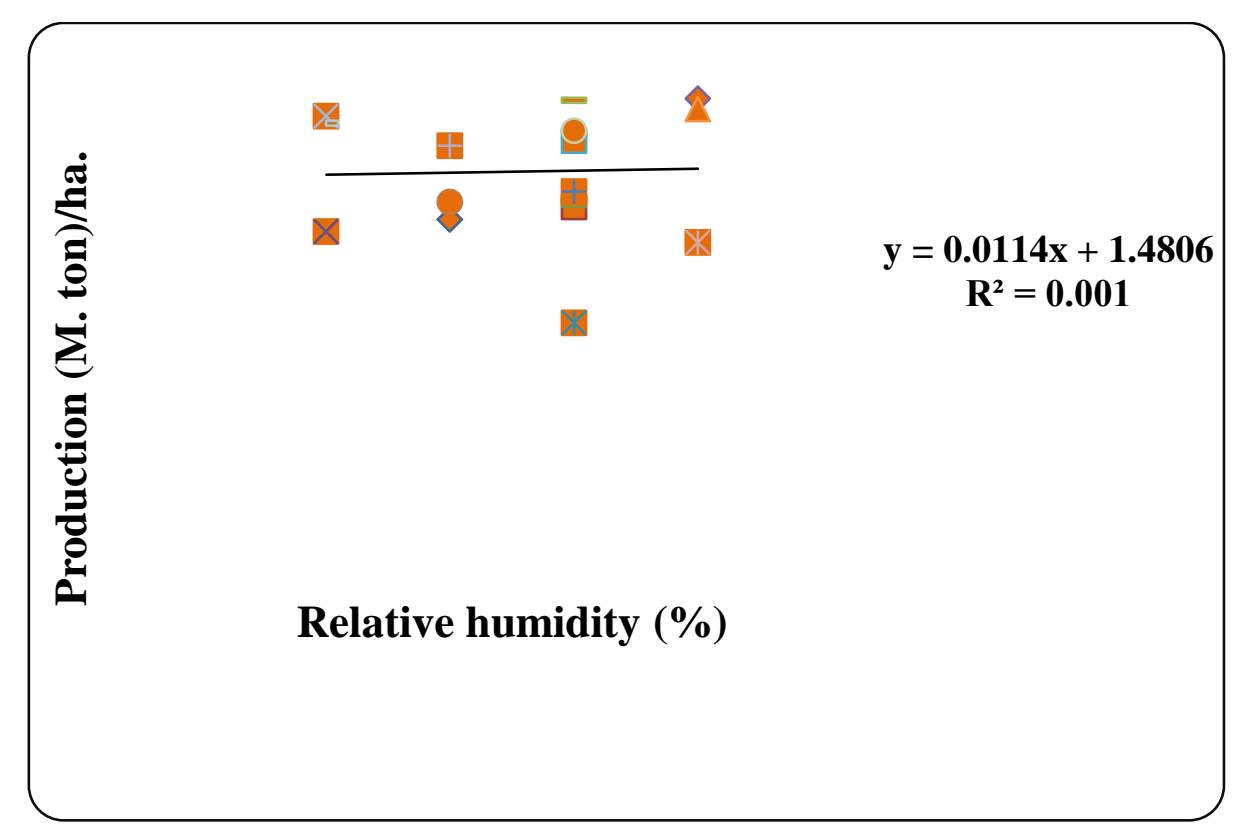

Fig. 9a. Correlation between Aman production and relative humidity period (1994-2010).

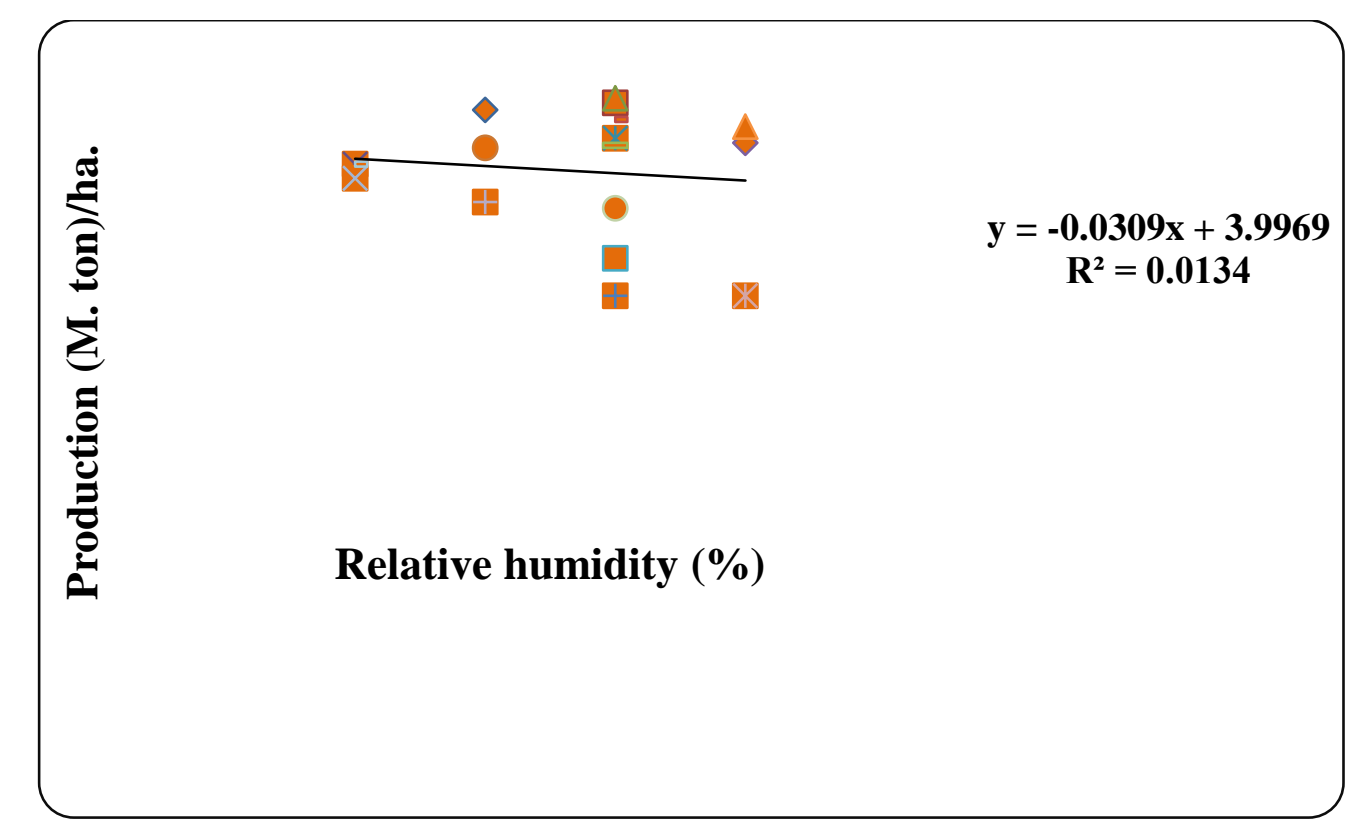

Fig. 9b. Correlation between Lona Coche production and relative humidity period (1994-2010). 


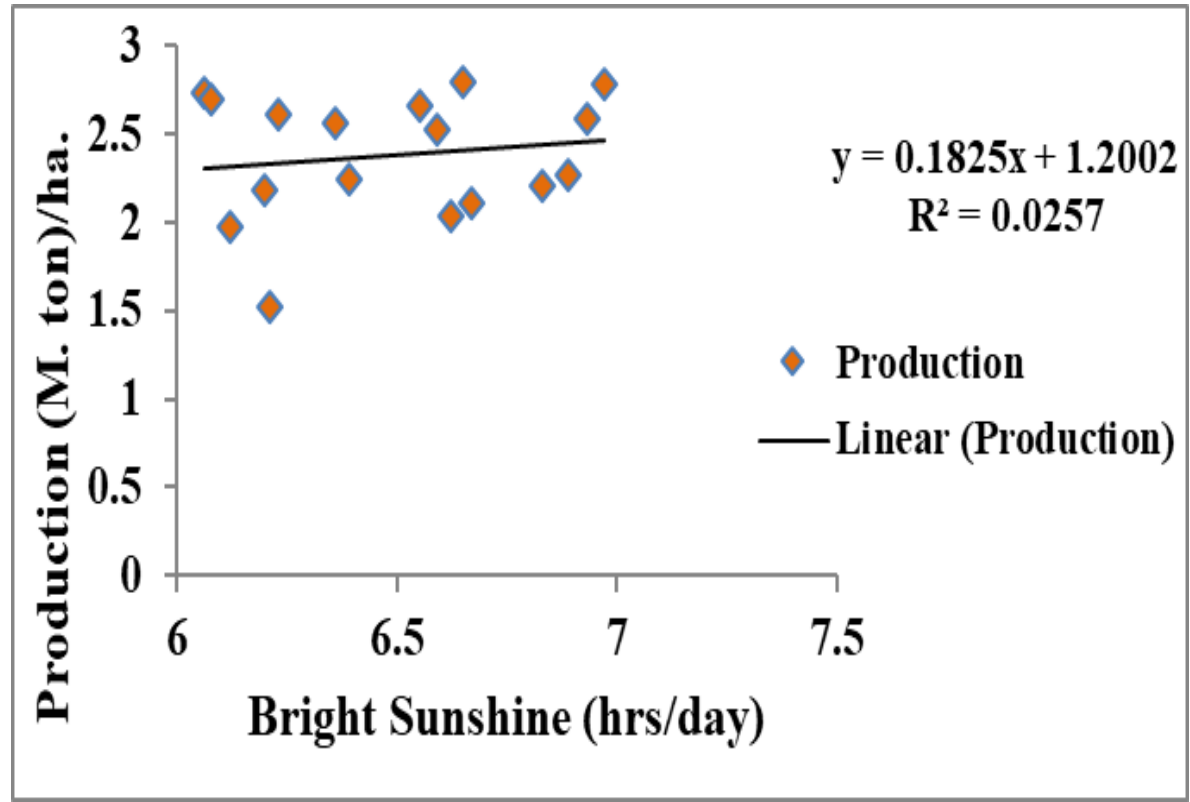

Fig. 10a. Correlation between Aman production and bright sun shine period (1994-2010).

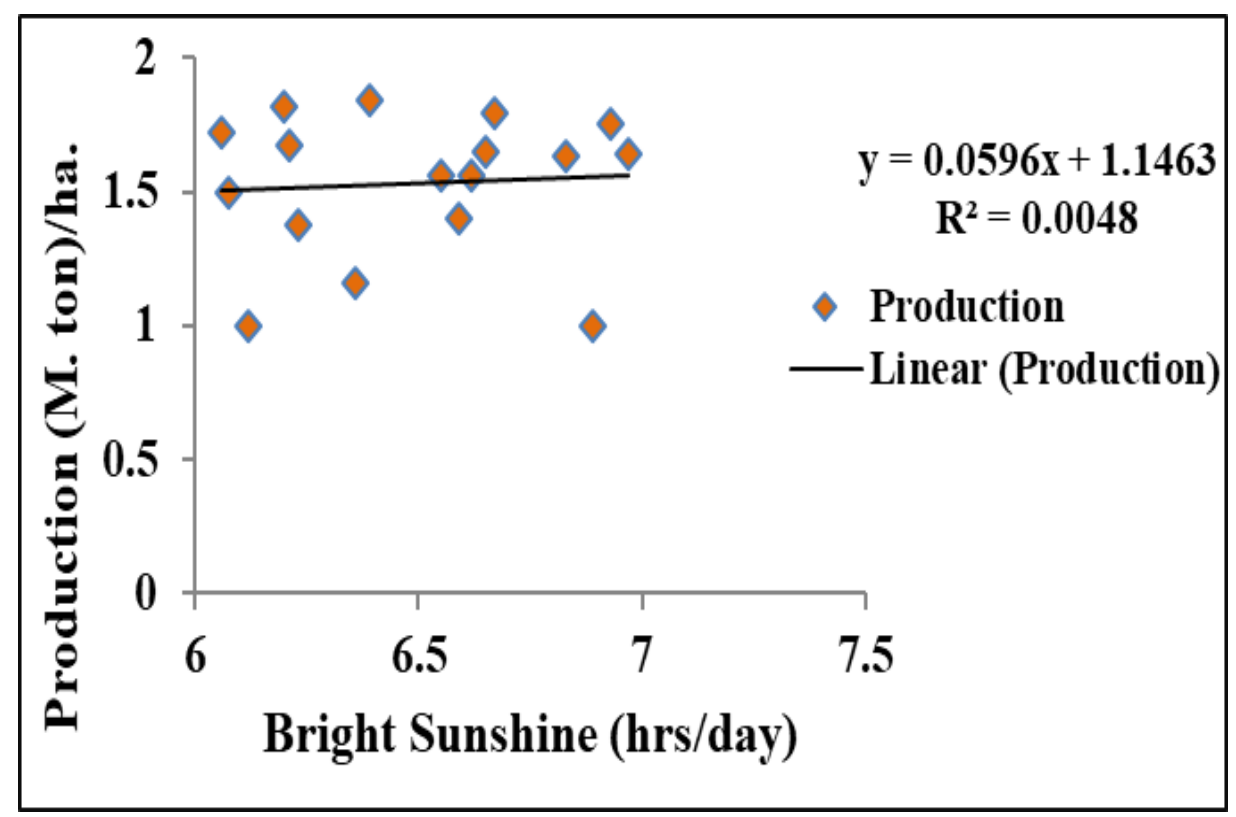

Fig. 10b. Correlation between Lona Coche production and bright sun shine period (1994-2010).

\section{Acknowledgements}

The authors acknowledged the contribution of the Bangladesh Meteorological Department (BMD) for making climatologic data available to us. Thanks, are also due to the department of Environmental Science and Resource Management, Mawlana Bhashani Science and Technology University, Department of Agricultural Extension (DAE), Khulna and Soil Resource Development Institute (SRDI), Khulna for their supports and help carrying out the study. They also thank the anonymous reviewers who provided valuable comments on the paper. 
Tab. 2. Mann-Kendall trend test of Temperature and Rainfall of study area.

\begin{tabular}{|c|c|c|c|c|c|c|}
\hline Year & $\begin{array}{l}\text { A number } \\
\text { of yrs. }\end{array}$ & month & $\begin{array}{l}\text { Mann- } \\
\text { Kendall } \\
\text { trend (Z) }\end{array}$ & $\begin{array}{l}\text { Sen's slope } \\
\text { estimate (Q) }\end{array}$ & $\begin{array}{l}\text { Parameter of } \\
\text { test }\end{array}$ & $\begin{array}{l}\text { Year of } \\
\text { observation }\end{array}$ \\
\hline \multirow{11}{*}{$\begin{array}{l}\stackrel{0}{0} \\
\stackrel{1}{1} \\
\grave{1} \\
\infty \\
0\end{array}$} & 30 & June & $-1.26^{\mathrm{NS}}$ & -3.167 & \multirow{6}{*}{ 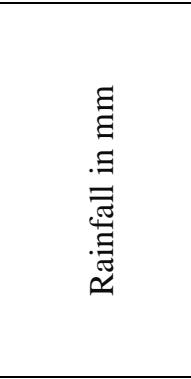 } & \multirow{5}{*}{$\begin{array}{l}0 \\
\stackrel{0}{0} \\
\text { 1 } \\
0 \\
\infty \\
0\end{array}$} \\
\hline & 30 & July & $1.38^{\mathrm{NS}}$ & 3.880 & & \\
\hline & 30 & August & $-1.63^{\mathrm{NS}}$ & -3.923 & & \\
\hline & 30 & Sept. & $2.67 * *$ & 7.074 & & \\
\hline & 30 & Oct. & $0.22^{\mathrm{NS}}$ & 0.500 & & \\
\hline & 30 & $\begin{array}{l}\text { Monsoon } \\
\text { Average } \\
\text { Rainfall }\end{array}$ & $0.78^{\mathrm{NS}}$ & 3.604 & & \\
\hline & & June & $-0.39^{\mathrm{NS}}$ & -0.050 & \multirow{5}{*}{ 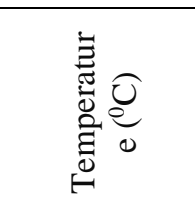 } & \\
\hline & & July & $-1.34^{\mathrm{NS}}$ & -0.200 & & \\
\hline & & August & $-1.34^{N S}$ & -0.150 & & \\
\hline & & Sept. & $-2.19^{*}$ & -0.133 & & \\
\hline & & Oct. & $-2.73 * *$ & -0.200 & & \\
\hline \multirow{2}{*}{ 항요 } & 16 & Lona Coche & $-2.27 *$ & -0.024 & \multirow[t]{2}{*}{ Yields } & \multirow[t]{2}{*}{$1980-2010$} \\
\hline & 16 & Aman & $2.02^{*}$ & 0.039 & & \\
\hline
\end{tabular}

${ }^{*} \alpha=0.001$ level of significance, ${ }^{* *} \alpha=0.01$ level of significance, ${ }^{* * *} \alpha=0.05$ level of significance, NS=Non-significant.

\section{References}

Amin MR, Zhang J, Yang M (2015) Effects of Climate Change on the Yield and Cropping Area of Major Food Crops: A Case of Bangladesh. MDPI, Journal of Sustainability, 7, 898-915.

Ahmed AU and Alam MA (1999) Development of Climate Change Scenarios with General Circulation Models, In Vulnerability and Adaptation to Climate Change for Bangladesh. S. Huq, Z. Karim, M. Asaduzzaman and F. Mahtab (Eds.): 13-20.

Ali MH (2010) Fundamentals of irrigation and on-farm water management: volume 1. Agricultural engineering division, Bangladesh Institute of Nuclear Agriculture, Bangladesh agricultural university, Mymensingh, Bangladesh. Springer, New York, 2010.

Banglapedia (2014) National Encyclopedia of Bangladesh. 2014. http://en.banglapedia.org/index.php?title=Koyra Upazila.

Bangladesh Meteorological Department (BMD) (2013) Data Collected from BMD Headquarter at Dhaka (Climate Section), Bangladesh on 15 December.

BBS (Bangladesh Bureau of Statistics) (2002) Statistical Year Book of Bangladesh. Bangladesh Bureau of Statistics, Bangladesh, Dhaka.

BRRI (2006) Improvement of standard Boro Rice. BRRI (Bangladesh Rice Research Institute) Annual Report for July 2005-June 2006. Plant Breeding Division, BRRI, Gazipur, Bangladesh.

Chowdhury IUA, Khan MAE (2015) The impact of climate change on rice yield in Bangladesh: a time series analysis. Russian Journal of Agricultural and Socio-Sciences 4:40.

Ferdous MG, Baten MA (2011) Climatic Variables of 50 Years and their Trends over Rajshahi and Rangpur Division. Journal of Environmental Science \& Natural Resources, 4(2), 147-150.

Hossain MN, Rahman MM, Islam K (2016) Vulnerability of Agricultural Production due to Natural Disaster at Mongla Upazila (sub district) in Bangladesh. British Journal of Applied Science \& Technology, 16(1), 1-13.

Hossain, MF, Islam MS, Rahman MM, Faruk MO, Ershad MG (2008) Yield and quality performance of some aromatic rice varieties of Bangladesh. J. Agro. for Environ. 2(2), 155-158.

Intergovernmental Panel on Climate Change (IPCC) (2007) Climate Change: Impacts, Adaptation and Vulnerability. In Contribution of Working Group II to the Fourth Assessment Report of the Intergovernmental Panel on Climate Change; Cambridge University Press: Cambridge, UK.

Karim Z, Hussain Sk G, Ahmed AU (1999). Climate Change Vulnerability of Crop Agriculture. Springer Netherlands. pp 39-54. 
Lai M, Whettori PH, Pittodi AB, and Chakraborty B (1998) The greenhouse gas induced climate change over the Indian Sub-continent as projected by GCM model experiments. Terrestrial. Atmospheric and Oceanic Sciences, TAO, 9(iv): 663-669.

Mistri NA, Rahman M, Khatun T (2015) Climate Change and Food Security at Salinity Prone Area in Southwest Coastal Region of Bangladesh. International Journal of Environmental Protection and Policy. Special Issue: Advances in Environmental Researches. 3,35-39.

Masud-Al A, Liza AK, Azad AK (2014) Vulnerability of crop production to climatic variability in a water stress area of the north-west region of Bangladesh: a case study in the Sapahar Upazila under Naogaon District. IOSR Journal of Environmental Science, Toxicology and Food Technology. 8 (5), 41-52.

Ministry of Environment and Forest (MOEF) (2009) Bangladesh Climate Change Strategy Action Plan; Government of the People Republic of Bangladesh: Dhaka, Bangladesh.

Marshall R, Haferkamp (1988) Environmental factors affecting productivity. Published by Montana, Agr. Exp. Sta. Bozeman, 132p.

Mirza MMQ (2002) Global warming and changes in the probability of occurrence of floods in Bangladesh and implications. Global Environmental Change 12,127-138

Rimi RH, Rahman SH, Karmakar S, Hussain SG (2009) Trend Analysis of Climate Change and Investigation on its Probable Impacts on Rice Production at Sathkhira, Bangladesh. Pak. J. Meteorol. $6,37-50$

SRDI (Soil Resource Development Institute) (2000) Land and Soil Resource Utilization Suides, Upazilla Nirdeshika, Khulna and Barisal Division, Ministry of Agriculture, Dhaka -1215.

Seal L, Baten MA (2012) Salinity Intrusion in Interior Coast: A New Challenge to Agriculture in South Central part of Bangladesh". Unnayan Onneshan -The Innovators.

World Bank (2000) Bangladesh: Climate Change and Sustainable Development. Report No. 21104-BD Rural Development Unit South Asia Region. The World Bank Dhaka, pp. 95.

Yuji M, Kiyoshi T, Hideo H, Yuzuru M (2009) Impact assessment of climate change on rice production in Asia in comprehensive consideration of process/parameter uncertainty in general circulation models. Journal of Agriculture, Ecosystems and Environment. 131, 281-291.

Zhang, Y-Q, Cai Y-X, Beach RH, McCARL BA (2014) Modeling Climate Change Impacts on the US Agricultural Exports. Journal of Integrative Agriculture. 13(4), 666-676. 